\title{
APRESENTAÇÃO DA SESSÃO TEMÁTICA
}

\author{
Edmea Oliveira dos Santos \\ Felipe Carvalho \\ Rosemary dos Santos
}

A Revista Teias apresenta a sessão temática Redes Educativas e mediacõos digitais: tensões e insurgências de formação que visa estabelecer o bom debate para a compreensão de redes educativas como elementos conceituais do currículo, fazendo emergir criações curriculares no/do pensamento contemporâneo.

Com essa perspectiva, a articulação entre educaşão, cultura e processos culturais tem sido buscada a partir do entendimento de que tensões e insurgências de formação criam uma diversidade de possibilidades para a criação de conhecimento. Processos de formação docente possibilitam-nos pensar sobre desafios de educar em nosso tempo e sobre o fato de precisarmos repensar os currículos em tempo de cibercultura, nas diversas redes educativas. Uma delas, a universidade. A docência é atividade complexa e desafiadora, o que exige do professor constante disposição para aprender, questionar e investigar sobre, como, e por que ensinar. Em sociedade de constantes mudanças e infinitas incertezas, as exigências para o exercício da docência têm sido cada vez maiores.

A articulação proposta, portanto, implica pensar valores que vêm mudando aceleradamente nas diferentes áreas sociais, políticas e econômicas a partir de ações coletivas. Mudanças que inspiram invenções epistemológico-teórico-metodológicas nas diferentes áreas do conhecimento humano. O conhecimento gerado se materializa, cada vez mais, pelas mediações digitais, por suas tensões e insurgências, aqui entendidas como criações culturais, cujos usos e aplicações são definidos pela atuação direta dos sujeitos em cada momento sócio-histórico, político e social em que vivem, compartilham, cocriam e interagem, (re)criando múltiplas linguagens e, sobretudo, ampliando os fundamentos interdisciplinares contemporâneos.

Esta sessão temática pode trazer contribuições de vários professores de universidades públicas brasileiras em múltiplas pesquisas em que buscam compreender diferentes cotidianos e as tantas redes educativas nos quais formamos e somos formados. Diante de tensões e insurgências que requerem concepções de conhecimento ampliadas, com enfoques para além dos contextos vinculados estritamente às instituições educativas, discutem-se as práticas a partir das emergências culturais. Procurou-se, para isso, operar com dispositivos capazes de acionar memórias e provocar outros olhares sobre o trânsito/fluxo entre imagens, cotidiano, pedagogias, mediações digitais e currículos, nas contingências da contemporaneidade.

Iniciamos a sessão temática com o artigo de Mitsi Pinheiro de Lacerda denominado Apenas três fotografias cotidianas, que apresenta breve estudo abordando a interface entre fotografia e vida cotidiana, enquanto tema. O objetivo da autora foi buscar aproximações entre as contribuições oferecidas por Roland Barthes e José de Souza Martins no que se refere à produção e uso da fotografia, e entre os delineamentos teóricos postos por Michel de Certeau, Agnes Heller e Henri Léfèbvre, em relação à vida cotidiana. A pesquisa destaca aspectos da fotografia e da vida cotidiana associados à imprevisibilidade, criatividade, liberdade e autoria, observando os usos contemporâneos da produção de imagens nos cotidianos - registrados e expostos excessiva e publicamente. 
No artigo Games e aprendizagens na perspectiva histórico cultural as autoras Adriana Rocha Bruno e Janaina de Oliveira Nunes Ribeiro buscaram compreender como se dão processos de ensino e de aprendizagem a partir da interação com jogos digitais, tomando por base a teoria histórico cultural de Vigotsky e os estudos clássicos sobre jogo, sociedade e educação, de Huizinga, Caillois e Brougère, assim como perspectivas contemporâneas de pesquisadores que se debruçam a estudar relações entre jogos digitais e educação.

Ainda na perspectiva de estudos dos games, o artigo Game of Thrones, interações em rede e experiências formativas em história de Cristina D'Ávila, Edmea Santos e Társio Roberto Macedo evidencia um conjunto de argumentos teórico-metodológicos que explicitam a relação entre a série televisiva Game of Thrones, interações em rede e experiências formativas em História, no contexto da cibercultura. Os fenômenos experienciados no campo de pesquisa confirmam que as redes assimilam e trabalham com um potencial lúdico-formativo a partir da heterogeneidade dos imaginários aprendentes e suas sensibilidades, quando se pretendem formações em História.

As autoras Katia Ethiénne dos Santos, Raquel Pasternak Glitz. Kowalski e Sueli Perazzoli Trindade apresentam, no artigo Formação docente para a produção de material para a educação digital, reflexões sobre a formação de docentes envolvidos com a produção de materiais para a educação digital, que envolve tanto a educação em todo tempo e lugar em contextos não formais, como a educação a distância e a educação híbrida. O foco está na educação híbrida/semipresencial que se entende ter um papel relevante na inserção de tecnologias e na mudança de paradigmas na graduação e pósgraduação, impulsionando a formação de professores para que atuem de modo mais efetivo, inserindo tecnologias no cotidiano educacional.

No artigo Tecnologias digitais, literatura infantil e multiletramentos na formação de professoras, Terezinha Fernandes busca compreender a relação entre literatura infantil e tecnologias digitais na obra literária $A$ vida de Ada Lovelace discutindo insurgências, tensões e multiletramentos na formação de professoras que atuam com crianças. A pesquisa foi desenvolvida com inspiração na metodologia da pesquisa-formação, na disciplina Múltiplas linguagens: literatura infantil, em um curso de licenciatura.

Em Práticas de ensino com o uso de tecnologias digitais: o papel da formação docente, Ariane Xavier de Oliveira, Diene Eire de Mello e Sandra Aparecida Pires Franco, promovem discussões acerca do papel da formação de professores enquanto mobilizadoras de boas práticas com tecnologias digitais. Tratase de um estudo qualitativo de caráter exploratório que utilizou, como fonte de dados, entrevistas e consulta a documentos oficiais. De posse dos dados analisados foi possível apreender a relevância da formação em serviço como mobilizadora de boas práticas com esses artefatos culturais.

No artigo Os movimentos ciberativistas de (re)existência nas redes sociais e suas implicações para a educação, Dilton Couto Junior, Luciana Velloso e Rosemary dos Santos nos inspiram a repensar o cenário político contemporâneo e os usos das tecnologias digitais, cuja especificidade na produção e no compartilhamento de dados informacionais rompem com a centralidade da mídia de massa. Em torno do movimento \#ELENÃO, que envolveu a participação de milhões de internautas de todos os cantos do Brasil em setembro de 2018, apresentam movimentos de (re)existência orquestrado por mulheres na rede, trazendo implicações para o campo da educação, principalmente quando se reconhece o Facebook como importante espaço de mobilização social.

Com a discussão sobre Mediação digital na aquisição da leitura e escrita de surdos: análise linguísticodiscursiva da produção textual a partir do gênero mensagem instantânea, os autores Hector Renan da Silveira Calixto, Huber Kline Guedes Lobato e José Anchieta de Oliveira Bentes analisaram a produção escrita de educandos surdos, que eram atendidos no contraturno em uma sala de recursos multifuncionais na cidade de Belém, no Pará. Os autores problematizam diferentes formas de interagir e estar no 
DOI: https://doi.org/10.12957/teias.2020.48635

mundo de estudantes surdos, demonstrando que, para eles, deve-se abandonar o ideal grafocêntrico da cultura majoritária que se ancora na ideia de oralidade/escrita como questão de urgência, entre professores, de modo que estudantes surdos possam ser respeitados como pessoas cuja forma idiossincrática de escrita seja considerada no ambiente educativo.

O texto O processo da formação continuada dos professores das salas de recursos multifuncionais para o uso da tecnologia assistiva de Degiane da Silva Farias e Mayara de Oliveira Vieira traz como proposição refletir sobre como vem se constituindo o processo de formação continuada de professores para o uso da Tecnologia Assistiva, tomada como todo o conjunto de equipamentos, de recursos e de serviços que dão condições às pessoas com deficiência de ter maior independência e autonomia, promovendo a inclusão. O estudo, segundo as autoras, trouxe como resultados denúncias relacionadas à ausência de materiais pedagógicos, de equipamentos e de formação voltada para a inclusão e para o uso de novas tecnologias, a exemplo da tecnologia assistiva.

$\mathrm{Na}$ temática que contempla tensões e insurgências de formação, o artigo \#UERJRESISTE: a politização de si através das selfies de Felipe Carvalho e Fernando Pocaby mostra como a rede social Facebook vem possibilitando aos usuários a tematização de fotos de perfil - selfies - a partir da abertura a marcações de posicionamento político ou de adesão a determinados movimentos, articulados a causas e/ou princípios ético-políticos. A pesquisa dos autores, aqui relatada, buscou compreender o modo como as mobilizações politizadas de selfies se articulam nos cotidianos de sujeitos vinculados ao espaço acadêmico.

Com o artigo Desenvolvimento profissional do pedagogo escolar e as tecnologias: perspectivas a partir da especificidade funcional e formação docente na escola, as autoras Glaucia da Silva Brito e Michele Simonian Dj̈ck apresentam o que apontam pedagogos escolares em relação às tecnologias para processos formativos, identificando, assim, necessidades formativas como resultados da pesquisa. Evidenciam, nas conclusões, o vislumbre de uma proposta de desenvolvimento profissional a partir das reais necessidades dos pedagogos escolares.

Em As mídias no cotidiano da educaşão infantil na perspectiva dos acadêmicos do curso de pedagogia as pesquisadoras Dulce Márcia Cruq, Klalter Bez. Fontana Arndt, Lidnei Ventura problematizam como as mídias aparecem no contexto da educação infantil, qual a percepção dos acadêmicos sobre elas e quais as possibilidades de usos nesse contexto. Para compreensão do fenômeno, lançaram mão de um roteiro de observação e projeto de intervenção docente. Os resultados apontam que é essencial o debate sobre tais questões no processo formativo docente, em especial, na formação inicial dos professores.

Em Autonarrativa epistolar: um olhar sensivel de um estrangeiro sobre o Brasil, Victor Amar apresenta um exercício de expressão em que mostra parte de sua identidade. Com metodologia qualitativa, a discussão e os resultados são veiculados fornecendo uma rede de conclusões que vêm nutrir o valor da comunicação; do fato comunicativo. As cinco cartas dão a conhecer uma parte do sentir do autor quando a subjetividade adquire seu protagonismo.

Fechamos essa sessão especial com o artigo $A$ hiperescrita de si: memória, experiência e invenção digital na formação de professores de Tania Lucia Maddalena, professora que, de longe, da Universidade Internacional de La Rioja (UNIR), Espanha, apresenta o processo de escrita de si e os fortes impactos que se potencializam quando a escrita é feita em rede e a experiência de formação é compartilhada no ciberespaço. A autora parte do diálogo teórico-metodológico e epistemológico de pesquisas autobiográficas em educação, de pesquisas com os cotidianos escolares e de metodologias que defendem o valor da prática, sem separar pesquisa do contexto da docência.

Rio de Janeiro, jan.-mar. 2020. 
DOI: https://doi.org/10.12957/teias.2020.48635

\section{Informações do(as) editor(as)}

Edméa Oliveira dos Santos

Profa. Titular-livre da Universidade Federal Rural do Rio de Janeiro (UFRRJ)

E-mail: edmeabaiana@gmail.com

ORCID: http://orcid.org/0000-0003-4978-9818

Link Lattes: http://lattes.cnpq.br/4023554724278836

Felipe da Silva Ponte de Carvalho

Universidade do Estado do Rio de Janeiro (UERJ) / Universidad Complutense de Madrid (UCM).

Bolsista de Doutorado-Sanduíche Faperj

E-mail: felipesilvaponte@gmail.com

ORCID: https://orcid.org/0000-0001-7398-6171

Link Lattes: http://lattes.cnpq.br/8539464540238508

Rosemary dos Santos

Prof ${ }^{a}$. da Universidade do Estado do Rio de Janeiro (UERJ)

E-mail: rose.brisaerc@gmail.com

ORCID: https://orcid.org/0000-0003-0479-1703

Link Lattes: http://lattes.cnpq.br/9464170521679409 